\title{
OS ESTADOS-LIMITE NOS TRABALHOS PSICANALÍTICOS FRANCESES'
}

\section{Jean Yves Chagnon}

Resumo: Após uma breve introdução histórica e um esclarecimento terminológico, o quadro psicopatológico clássico das organizações-limite, descrito por Kernberg, está resumido tanto na sua dimensão clínica, estrutural, como genética. As diferentes correntes psicodinâmicas contemporâneas são lembradas; em seguida, os principais trabalhos psicanalíticos de língua francesa são apresentados, tanto a respeito dos adultos (Bergeret, Green) como das crianças e adolescentes (Diatkine, Mises, Jeammet). A especificidade teórica da psicanálise francesa, ligada tanto ao impulso como às relações de objeto, à intra-psíquica como ao intra-subjetivo, é destacada.Uma síntese atual (Brusset,Chabert) é proposta baseada em três problemáticas principais: a patologia do transtorno borderline e a falta de interioridade, a angústia da perda do objeto, as particularidades do conflito edipiano e o masoquismo. $O$ peso das modificações psicossociais e culturais contemporâneas sobre as mudanças da psicopatologia é aqui evocada.

Palavras-chave: Distúrbio da personalidade borderline. Relações de objeto. Narcisismo. Masoquismo. Psicanálise. Psicoterapias psicanalíticas.

\section{Introdução: história e terminologia}

Sabemos que o interesse dos psiquiatras pelos "estados fronteiriços da loucura", ou seja, as formas subclínicas das psicoses data do final do século XIX. Era um interesse a respeito de pacientes que não apresentavam sintomas psicóticos manifestos, mas aos quais atribuíamos uma psicose subjacente ou para os quais esses sintomas não tinham ainda eclodido. A questão das fronteiras (e de sua estabilidade) espaciais

1 Tradução efetuada por Rosa Passos e revisão técnica de Sonia Regina Pasian e Jesé Alvaro Lelé. 
e temporais das doenças mentais foi bem cedo levantada (Bergeret, 1974, 1975; Brusset, 1999; Bourgeois, 2004). A partir de tais interrogações chegamos à definição pelo DSM IV da "personalidade borderline" incluída no vasto quadro dos transtornos de personalidade. Observemos que se trata de uma tentativa da psiquiatria quantitativa centrada em uma análise semiológica descritiva e objetiva dos sintomas e dos comportamentos, deixando obscuro o lugar, a função e a significação desses na economia psíquica sempre singular do sujeito. Ela não diz nada sobre a história do indivíduo e nem sobre o contexto do ambiente, relacional e social, nos quais esses sintomas são produzidos e lhe dão sentido.

É bem diferente a tentativa psicanalítica quando aborda a Psicopatologia. Na realidade, a psicanálise se interessa pelo funcionamento mental, amplamente inconsciente nas suas modalidades e suas determinações, tanto que pode ser deduzido do discurso do sujeito dirigido ou comunicado ao psicanalista. A semiologia abordada pelo psicanalista é uma semiologia original, extraída da entrevista de investigação ou da sessão e, particularmente, das associações livres que nela ocorrem, subentendidas pela transferência. Acrescentemos que, nessa perspectiva, o normal e o patológico não são considerados como radicalmente estranhos um ao outro: os conflitos vivenciados (posição depressiva, complexo de Édipo, por exemplo) pelo sujeito perturbado são os mesmos existentes no sujeito normal, mas eles são tratados diferentemente (Chabert, 1999; Widlocher, 1984).

A noção de "estado-limite" ou, ainda, de caso-limite (tradução de transtorno borderline) revela, assim, inúmeras preocupações dos psicanalistas. Estes descobriram que pacientes considerados como neuróticos desenvolveram, no quadro da terapia psicanalítica, modos de funcionamento psicótico, regressivos e temporários ou mais duradouros. Surgiu, assim, a preocupação em resgatar esses pacientes e em encontrar recursos técnicos para tornar o trabalho psicanalítico possível. Houve o surgimento de uma eflorescência de trabalhos, especialmente após a Segunda Guerra Mundial, tanto na Europa como na América do Norte, a tal ponto que podemos considerar hoje os estados-limite como um novo paradigma: eles são para a psicanálise atual aquilo que a histeria era outrora.

No início, o estado-limite era conceituado como próximo do limite, ou seja, da linha de demarcação entre a neurose e psicose - que essas sejam concebidas como diferentes uma da outra ou situadas em um contínuo. Retomavam, então, os limites das classificações nosológicas, incluindo as do tipo psicanalíticas, referentes às estruturas de personalidade. Depois o termo estado-limite pouco a pouco se tornou sinônimo de um modo de organização ou de estrutura psíquica intermediária entre neurose e psicose e, ainda, com duas perspectivas. Uma delas situa o estado-limite como utilizando modalidades heterogêneas (neuróticas e psicóticas) e o concebe como instável; a outra o coloca como um modo de organização original, mais ou menos estável, e situado em um eixo mediano entre neuroses e 
psicoses. Esta é a posição do pioneiro Kernberg $(1975,1984)$. Finalmente uma terceira definição tende a aparecer atualmente, a definição de funcionamento-limite como universal, mas atualizando-se somente em certas condições ambientais (de onde vem o peso das modificações psicossociais contemporâneas na eclosão atual dos estados-limite) ou no contexto regressivo da terapia.

Essa estaria essencialmente centrada sobre as neuroses, organizadas em torno do complexo de Édipo, favorecendo a revisão, na atualidade, dos limites do analisável e fazendo interrogar a categoria do "arcaico" (Green, 1982). Os mais significativos avanços teórico-clínicos e técnicos da psicanálise tiveram, inevitavelmente, um ponto de vista genético onde o"precoce, o primitivo",as relações primárias com a figura materna, foram interrogadas, especialmente na sua dimensão patogênica, traumática, e revisitadas na relação transfero-contratransferencial. Assim, os pioneiros do estudo dos estados-limite são aqueles que contribuíram para o estudo dos estágios pregenitais e das precoces relações de objeto: Ferenczi, Balint, Fairbairn e Winnicott, sem esquecer do último, Freud (1937/1985), que afirmava a existência de um núcleo psicótico subjacente a todo funcionamento neurótico, perspectiva que será particularmente desenvolvida por M. Klein.

Entre os clínicos contemporâneos, Kernberg (1975) foi um dos primeiros a sistematizar o estudo das organizações-limite - termo que ele prefere ao de "estado" para mostrar o caráter estável - tanto no plano clínico, psicopatológico, quanto psicoterápico, através de numerosos trabaIhos, tendo influenciado ou estimulado a abordagem francofônica, a qual pode-se dizer que estabelece um consenso: aliás, eles foram amplamente retomados pelo DSM.

A angústia difusa e flutuante, os sintomas de aparência neurótica, os traços de personalidade infantil, depressiva e masoquista ou narcísica, as tendências impulsivas na passagem ao ato auto ou hetero-agressivo e as condutas antissociais, minimamente as dificuldades relacionais, a dependência toxicomaníaca e as condutas sexuais desviantes constituem habitualmente a semiologia segundo as variações próprias a cada caso: se certas organizações-limite não descompensadas funcionam sem dificuldades ou distúrbios maiores, outras mais frágeis engajam-se em vidas infelizes, vidas de "galera" (Chabert, 1999), mais ou menos marcadas pela exclusão social, convocando repetidamente a psiquiatria, os sistemas de assistência ou as instâncias judiciárias e penitenciárias.

No plano estrutural, Kernberg evoca uma fragilidade não específica do Ego (falta de tolerância à angústia, falta de controle pulsional, falta de desenvolvimento da sublimação), um retorno aos processos primários de pensamento, operações defensivas específicas (clivagem, recusa, identificação projetiva, idealização primitiva, onipotência e desvalorização) e, enfim, uma patologia das relações de objeto internalizadas: as identificações são superficiais, contraditórias, clivadas (bom/mau), como também as re- 
presentações de objeto permanecem cindidas. O Ego e o Superego estão mal integrados, o que determina uma síndrome de identidade difusa típica da organização-limite.

Para terminar essa introdução, observemos que o conceito de estado-limite se diferencia, assim, tanto no plano dos comportamentos que ele envolve como no método utilizado, do TBP (Transtorno Borderline da Personalidade) do DSM IV. Esse último seria somente uma das expressões comportamentais possíveis do estado-limite, que pode também dar lugar a uma expressão esquizoide ou narcisista. Atualmente, várias correntes, bem resumidas e postas para dialogar em um recente documento francocanadense (Guilé, 2004a, 2004b), contribuem para a reflexão psicanalítica e psicopatológica sobre os estados-limite: uma corrente baseada no conceito de apego (Fonagy).Trata-se de uma corrente anglo-saxônica que, depois de Fairbairn e Kernberg, desenvolveu a teoria das relações de objeto e dos déficits de interiorização próprios aos estados-limite, depois chegou a uma valorização das relações interpessoais ou ainda intersubjetivas (Renik).Tem correspondência a uma corrente francesa que reserva, no plano da teorização, um lugar importante para a dimensão pulsional, à agressividade e à destruição (a violência fundamental), mas também à sexualidade infantil (o sexual) e aos conflitos edipianos, juntamente com o conflito depressivo e as falhas do narcisismo.

Essencialmente, são esses os trabalhos que iremos apresentar aqui, tanto oriundos de clínicos de adultos (Bergeret, Green), como de clínicos de adolescentes (Jeammet), antes de propor uma síntese atual (Chabert, Brusset \& Brelet-Foulard, 1999) e de mostrar como a reflexão psicopatológica sobre as patologias-limite desencadeou uma renovação na concepção teórica e técnica da abordagem psicanalítica. Nesse contexto, o enquadre foi revisto: atualmente a psicanálise não pode mais ficar restrita à cura no divã (Cahn, 2002).

\section{A contribuição dos psicanalístas de adultos}

Jean Bergeret $(1974,1975,1984,1996)$ é pioneiro nos estudos sistemáticos dos estados-limite, graças a inúmeras publicações escalonadas durante mais de 40 anos. Seu trabalho resultou numa descrição clínica e teorização especificamente metapsicológica, apoiada no esquema psicogenético, chegando a uma técnica terapêutica específica, dividida em duas etapas. Dessa forma, ele individualizou uma organização-limite original situada entre as estruturas neuróticas e psicóticas, não podendo se reduzir à coexistência de mecanismos de uma ou de outra linhagem. Trata-se, antes de tudo, de uma doença do narcisismo centrada na luta contra a depres- 
são, risco maior contra o qual lutam esses sujeitos. O núcleo psicopatológico comum aos estados-limite pode ser resumido da seguinte maneira:

- A angústia do estado-limite é uma angústia depressiva de perda do objeto, diferente da angústia de castração do neurótico e da angústia de destruição (fragmentação) do psicótico. Ao mesmo tempo, ela diz respeito a uma vivência infeliz quanto ao passado, porém acrescida de esperança de salvação investida na relação de dependência do outro (Greenson). A angústia depressiva ocorre assim que o sujeito imagina que o objeto que sustenta o seu narcisismo corre o risco de faltar.

- A relação do objeto anaclítico ${ }^{2}$ é uma relação dual com um objeto forte, grande, potente (fálico), sobre o qual o sujeito apoia-se ou se escora e pelo qual ele deve ser amado. Trata-se de um objeto total, separado, distinto de si, mas que permanece pregenital, não ainda no status edipiano, e do qual o sujeito fica dependente, no aguardo de satisfações positivas e de proteção. O luto é, então, impossível. Uma grande aproximação pode desencadear riscos de intrusão, no entanto, o sujeito-limite não pode ficar sem seu objeto e viver sozinho: sua alteridade é dificilmente reconhecida à medida da espera imaginária de uma realização total. Esse sujeito pode ser um objeto em pessoa, mas pode também ser um grupo, uma entidade abstrata (uma ideologia) ou um produto de substituição, quando o precedente venha a faltar.

- Um Ego fraco, fragmentado em duas partes, uma adaptativa voltada para a realidade exterior e, a outro, dita "anaclítica", fixada às necessidades narcisistas internas. Não se trata de uma clivagem psicótica fragmentada, mas de uma deformação do Ego que lhe permite não fragmentar. Pelo fato dessa dupla fragmentação, o Ego do sujeito-limite não pode se revestir de um grau de estruturação e de síntese que lhe permita uma real independência. Realmente, ele resiste mal às frustrações, o que o faz aparecer como um sujeito "esfolado vivo": seu narcisismo continua frágil, mal estabelecido, precisando de compreensão, de apoio e afeição, surgindo, assim, condutas sedutoras ou de domínio. Em caso de variação de distância ou recusa do objeto, ele pode desenvolver reações tempestuosas ou paranoides.

- As instâncias ideais são essencialmente organizadas ao redor de um Ideal de Ego megalomaníaco, ao passo que o Superego, habitualmente herdeiro do complexo de Édipo por identificações secundárias e interiorização das proibições fundamentais, permanece imaturo. $O$ sujeito-limite é mais movido por ambições heroicas em fazer bem, para poder conservar a presença e o amor do objeto, do que pela culpabilidade de fazer mal e o medo de ser punido pela castração. Mas, como diz o provérbio "o melhor é o inimigo do bem", esses sujeitos vivem dolorosa e vergonhosamente a constatação de um fracasso ou até mesmo de uma fraqueza entre suas ambições ideais (sem medida, inatingíveis) e as realizações do Ego, de onde surge o constante risco depressivo. A fraqueza do Superego, cujo valor pro-

2 Do grego anaklitos: virado para trás, deitado sobre as costas, de maneira passiva. 
tetor do narcisismo deve ser salientado, facilita a necessidade de ação, até mesmo a passagem para o ato em detrimento da mentalização e da verbalização das emoções e dos impulsos.

- Os mecanismos de defesa que têm como função distanciar a angústia, ou o desprazer, conservam um caráter primitivo custoso, em se tratando de energia. Trata-se da negação, da projeção (a identificação projetiva), da clivagem (dos objetos em bons/ruins), da idealização ou ainda da repressão e da evitação, especialmente das representações de desejo agressivo muito ameaçadoras para a manutenção da relação do objeto (o que não impede, às vezes, uma fuga brutal). Realmente, fragmentos de realidade interna ou externa não podem ser integrados e trabalhados (simbolizados), o que amputa o Ego e o enfraquece progressivamente.

No conjunto, configura-se como uma organização narcisista (narcisismo, Ideal do Ego, ferimento narcisista, vergonha, angústia da perda do objeto, depressão), podendo ser oposta a uma organização neurótica (Édipo, Superego, conflito genital, culpabilidade, angústia de castração, sintomas neuróticos). Para Bergeret, que propõe um esquema psicogenético, a organização-limite tem sua origem em traumatismos precoces que, sem esperar um efeito psicótico, têm um impacto desorganizador. Bloqueiam a evolução psicoafetiva em uma pseudolatência precoce, impedindo, assim, o complexo de Édipo (e sua resolução) de operar seu poder de estruturação sobre o psiquismo, mantendo o sujeito na angústia da perda do objeto. $\mathrm{O}$ adolescente entra em curto-circuito com os efeitos do amadurecimento. Esse bloqueio da maturidade afetiva do Ego constitui "o tronco comum dos estados-limite" que não se beneficiam de uma real estabilidade estrutural pelo fato de uma flutuação na identificação e na identidade. Esse tronco comum pode dar lugar a diferentes organizações perversas ou de caráter, mais ou menos estáveis, que o autor descreve em 1974. No entanto, essas também podem eclodir sob o peso de um segundo traumatismo, desorganizador, dando lugar a um episódio de angústia aguda, prelúdio de eventuais reorganizações estruturais em direção à via neurótica ou psicótica ou, ainda, a uma regressão psicossomática.

Essas observações sobre o impacto dos traumatismos precoces foram bastante abordadas, na atualidade, pelos pesquisadores quantitativos anglo-saxônicos (resumidas em Charrier \& Hirschelmann-Ambrosi, 2005), que mostraram a frequência de acontecimentos com características traumáticas presentes na infância das personalidades-limite. Pelo lado francófono, a clínica psicanalítica retomou amplamente Ferenczi, um pioneiro no assunto, trabalhando essa questão pela diferenciação de traumatismos sexuais e narcisistas, "quentes e frios", por excesso e por ausência. Seus aspectos desestruturantes sobre a construção do psiquismo puderam ser evidenciados assim que sua reativação na transferência e seus efeitos na contratransferência, bem como sobre o processo da cura, se tornaram o centro das preocupações dos psicanalistas contemporâneos (Brette, Emmanuelli, 
\& Pragier, 2005).Dando continuidade a sua obra, Bergeret (1984) trabalhará a questão da violência fundamental, violência do instinto de essência narcisista, diferente da pulsão e morte e que, nos casos de estados-limite, tem dificuldade para se integrar na estrutura genital edipiana.

A. Green é atualmente uma figura importante da psicanálise internacional: sua produção científica é impressionante, tanto em nível clínico, psicopatológico, metapsicológico, epistemológico, como técnico. Próximo de Lacan, sem jamais aprovar suas derivações técnicas (o silêncio sistemático, as sessões de duração variável e curtas), ele contribuiu com a introdução dos trabalhos dos psicanalistas de língua inglesa que permitiram a compreensão dos estados-limite (Bion, Winnicott). A ele devemos a invenção de inúmeros conceitos e noções utilizados atualmente, como a oposição narcisismo e vida-narcisista de morte (negativo), a alucinação negativa, a psicose branca, o complexo da mãe morta, o duplo limite, a função (des) objetalisante, a analidade primária, a posição fóbica central, o trabalho do negativo, a situação triangular etc. Sabemos que ele é um exemplar teórico e clínico sobre personalidades narcisistas (1983) e de casos-limite (1990, 1999), conceituados a partir da experiência analítica. Ele próprio propôs um modelo hipotético para os casos-limite em 1974, desenvolvido progressivamente em suas publicações posteriores, modelo que seguiremos aqui.

Para Green, que se baseia na definição freudiana bem conhecida da pulsão como conceito-limite entre o psiquismo e o somático (Freud, 1915/1978), o limite deve ser concebido como um conceito (Green, 1976/1990): o limite é considerado aqui como uma fronteira em movimento e flutuante, tanto na normalidade como na patologia. Ela não pode se formular em termos de representação figurada, mas em termos de processos de transformação de energia e de simbolização (força e significação), de zona de elaboração psíquica, intrapsíquica e intrasubjetiva (transicional). Ou seja, isso significa que as patologias-limite são, antes de tudo, patologias dos limites: do limite entre o interno e o externo do psiquismo do sujeito, mas também dos limites internos entre as diferentes instâncias de sua personalidade (pré-consciente-consciente / inconsciente segundo a primeira tópica, Id/ Ego/ Superego de acordo com a segunda tópica). Os casos-limite se situam então no no man's land, um território com fronteiras não definidas que o autor vai percorrer com a ajuda de conceitos ordenadores. As duas fronteiras hipotéticas do campo psíquico são: de um lado, o soma, e, do outro, o ato. Nos casos-limite, devido à carência do ambiente, por excesso (sobreinvestimento) ou por falta, a pulsão tem dificuldade para se representar a fim de dar lugar à ação específica em direção a um objeto confiável e seguro que traria a satisfação, transformando a situação de impotência em experiência satisfatória. Nesse lugar a pulsão é evacuada, descarregada no soma (somatização) ou na passagem ao ato (atuação), o que compromete a elaboração psíquica (muito dolorosa), o trabalho de ligação entre representações e afetos, aliás, frequentemente confundidos (Green, 
1999b). Enquanto isso, dentro do psiquismo, o Ego se auto-mutila por uma clivagem radical que torna impossível o trabalho de representação. Os outros mecanismos de defesa ditos primitivos ou ainda arcaicos (Green, 1982) são a consequência que leva um Ego, ao mesmo tempo vulnerável, rígido e sem coesão nem coerência, com limites indefinidos, ao pensamento comprometido. A depressão primária completa o quadro defensivo.Trata-se de um desinvestimento radical procurando obter um estado de vazio, de aspiração ao não-ser e ao nada, sob o peso da pulsão de morte e do narcisismo negativo. Esse mecanismo, descrito na psicose pura (Green \& Donnet, 1973), traduz-se clinicamente por um vazio de pensamento, a impossibilidade em representar, em pensar a impressão de estar com a cabeça vazia, surgindo um sentimento de não existência, de não realidade do Ego ou dos objetos, o que vem de encontro com a identidade descrita por Kernberg.

Se o modelo da neurose remete à angústia da castração, o modelo dos estados-limite remete à contradição da dupla angústia depressiva de separação (perda) / angústia paranoide de intrusão. A metáfora dos porcosespinhos em hibernação pode, desde já, ser usada para definir a relação de objeto dos casos-limite: longe demais eles se congelam, perto demais eles se espetam. Nessas condições, a ausência, que aqui não pode se assemeIhar a uma potencialidade de condição presente no crescimento psíquico do sujeito pelo desenvolvimento do pensamento, da imaginação e da criatividade, equivale a uma perda radical. A ausência, então, é impossível de constituir, de representar, estando o objeto muito próximo e intrusivo ou muito longe e abandonado. Secundariamente, o vazio pode ser invadido novamente pelo objeto ruim e por impulsos destrutivos: frente à ameaça de um confronto insuportável com o vazio, o sujeito "prefere", na realidade, manter uma relação sado-masoquista com o objeto negativo (interno/externo) sempre presente: o masoquismo. Essa tentação constante das patologias-limite pode, no entanto, passar a ser uma autodestruição quando se associa aos efeitos do narcisismo negativo, procurando unir a dependência e a passividade sempre sentida como ameaça de dominação pelo objeto onipotente (Green, 1982, 1993). O sujeito-limite oscila, assim, constantemente entre a tentação do nada e a procura (jamais concretizada) de um objeto totalmente satisfatório, mas fora do alcance por ser idealizado: pulsões de vida e de morte, de ligação e de desligamento aqui se confrontam indefinidamente em uma relação de desequilíbrio constante, que permanece, contudo, na área da "loucura privada" (Green, 1990), diferentemente da psicose. Os trabalhos de Green, sobre aquilo que ele mesmo chamará de estruturas não neuróticas (Green, 2002a), marcaram por muito tempo o pensamento psicanalítico francês e tiveram desdobramentos de uma atenção bem particular dada ao quadro e ao processo analítico que com ele se desenrola. Isso porque a indissociabilidade do pensamento e da relação de objeto, marcada aqui pelo furor desses sujeitos em defender seus limites contra a impiedade do objeto, colocava particularmente à prova o 
enquadre analítico e as funções do analista. É necessário também observar que a obra de Green representa uma parte da psicanálise francófona, que mesmo sempre atenta aos desenvolvimentos das teorias das relações de objeto essencialmente anglo-saxônicas, jamais abandonou a teoria pulsional (Green, 1997), especialmente a sexualidade, apesar da importância tomada aqui pela destrutividade, sempre atenta à complementaridade entre o intrapsíquico e o inter-subjetivo (Green, 2002a). Um eco desses debates encontra-se no $66^{\circ}$ Congresso de Psicanalistas de língua francesa, intitulado "Relações de objeto e modelos da pulsão" (Brusset, 2005a, 2005b).

Muitos outros psicanalistas franceses ou de língua francesa contribuíram de maneira significativa ao estudo dos casos-limite e das patologias narcisistas, ou seja, estruturas não neuróticas que são atualmente comuns para o psicanalista. Não podemos, dentro dos limites dessa comunicação, citar todos eles. Citemos, no entanto, os importantes trabalhos de:

- J. McDougall $(1978,1982,1989,1996)$, que, com a ajuda de um talento clínico notável, trata pacientes somatizadores, atuadores, drogadictos ou, ainda, apresentando perversões sexuais: ela propõe uma teorização original centrada na noção de histeria ou de sexualidade arcaica;

- R. Roussillon $(1991,1999)$ que desenvolveu a noção de sofrimentos narcisistas de identidade, questionando os paradoxos e situações-limite da psicanálise;

- Os conhecidos psicossomáticos da escola de Paris (Marty, De M'Uzan, \& David, 1963) que criaram o IPSO (Instituto de Psicossomática) juntamente com Marty (1990), Fain (1971) sozinho ou em companhia de Braunschweig (Braunschweig \& Fain, 1971, 1975), De M'Uzan $(1984,1997)$ e ainda Kreisler (1976), Kreisler, Fain e Soulé(1974), Szwec (1998), Smadja (2001). A hipótese dessa escola, amplamente confirmada atualmente, supõe que a mentalização (ligação entre representação-afetos) protege das desorganizações somáticas todo indivíduo que estiver suscetível a somatizar em função das variações de seu equilíbrio psicossomático;

- C.Balier (1988, 1996, 2005), psiquiatra-psicanalista que trabalhou em casas de detenção e que fez considerações clínicas e teóricas apaixonantes sobre o recurso ao ato (atuação) e à violência destrutiva, estudados a partir da delinquência criminal, em particular, a sexual. Atualmente, graças a ele, conhecemos melhor os funcionamentos incestuosos e pedófilos da perversão e da psicose;

- No que diz respeito aos autores de língua francesa, precisamos citar a corrente canadense organizada por Lussier $(1975,2006)$, corrente que tratou da patologia narcisista e da transferência limite (Bergeret \& Reid, 1986; Doucet \& Reid, 1996), onde ainda emergem contribuições psicodinâmicas importantes à psico-criminologia (Casoni \& Brunet, 2003). E, finalmente, a corrente suíça com Quinodoz (1991), que abordou a solidão e a angústia da separação, Ladame $(1987,1998)$, especialista em adolescentes border- 
line e suicidas, e Palacio-Espasa e Dufour (1995), psicanalistas de crianças que aprofundaram o campo das patologias-limite entre as crianças.

\section{A contribuição dos psicanalistas de adolescentes}

Não posso, dentro do tempo que aqui me é concedido, tratar dos trabalhos dos psicanalistas de crianças (Diatkine, Mises, Lang, \& Widlocher, citado por Chagnon \& Durand, 2007).

A psicopatologia psicanalítica do adolescente ocupa na França um lugar considerável e original, materializado pela criação, em 1983, por P. Jeammet e P. Gutton, da revista "Adolescência." Essa revista dialoga com os especialistas anglo-saxões (Blos, Laufer) e publica a maioria dos trabalhos inovadores, tendo principalmente esclarecido sobre as vicissitudes do desenvolvimento e características singulares da patologia dessa idade.

Para P. Jeammet (1994) o adolescente se depara com duas tarefas essenciais: remanejar suas identificações infantis (Marty, \& Chagnon, 2006) e, assim, integrar a nova imagem do corpo sexuado herdado da puberdade, o que lhe conduz a ter que assumir uma identidade de homem ou de mulher, confrontando-se com a diferença dos sexos e com a angústia de castração; a outra tarefa é estar mais distante e ter autonomia em relação aos seus pais. Esse duplo movimento conjunto questiona a solidez das interiorizações anteriores, principalmente em relação aos fundamentos narcisistas que permitem a libertação da dependência infantil. A adolescência, por seu impacto traumático, constitui, na realidade, um momento revelador da qualidade da organização narcisista prévia, criando condições de um possível antagonismo entre investimentos narcisistas e objetais, suscetível de gerar a base da psicopatologia do adolescente. A qualidade dos fundamentos narcisistas depende da qualidade da relação precoce entre pais-filho, do prazer vivenciado na troca objetal, gerando o autoerotismo e a capacidade de estar só. Resumindo, a segurança interior adquirida depende da interiorização, movimento infrarrepresentativo, de um apego seguro. Em consequência, quanto mais os limites entre o sujeito e o objeto forem sólidos, mais o Édipo terá organizado estruturas internas delimitadas, imagos diferenciadas e, assim, mais o conflito próprio à adolescência entre desejo objetal e necessidade de proteção narcisista será amortecido e terminará sobre uma retomada harmoniosa das identificações maduras. Ao contrário, quanto mais as carências narcisistas forem importantes e a dependência infantil mal-elaborada, mais os limites serão fluidos, a angústia da separação será intensa e o Édipo, excitante. Ainda nessa medida, as tarefas próprias à adolescência serão suscetíveis de terminar em um afastamento narcísico-pulsional (objetal, pois a pulsão é a representante do objeto no interior do Ego), incapacitando as possibilidades de relação 
objetal e, assim, de reaproximação do outro, por serem vistas como muito ameaçadoras para a identidade e a autonomia do sujeito.

Diferentes estratégias de relacionamentos e soluções comportamentais foram, a partir de então, utilizadas para organizar a dependência, a problemática fundamental da adolescência, segundo Jeammet e Corcos (2005). Elas vão de transições passageiras a organizações duráveis, que utilizam defesas psíquicas arcaicas, especialmente narcisistas (idealização / depreciação) e soluções comportamentais, indo da oposição banal às passagens ao ato (atuações) mais ou menos violentas. Aliás, a violência é concebida de maneira original, não como liberação pulsional agressiva ou destrutiva, porém como defesa narcisista-identitária frente às ameaças de perda e/ou de intrusão veiculadas pelo objeto. Mas esses comportamentos são repletos de potencialidades autodestrutivas: na realidade, P. Jeammet não parou de chamar a atenção sobre os riscos de autossabotagem masoquista próprios à patologia do adolescente, fascinado pelo negativo e pela fobia do prazer.

Se toda nosografia pode ser vista sob o vértice da organização da dependência, é essencialmente a patologia-limite que revela os fracassos. Diferentemente da psicose, que une a ameaça de intrusão / perda por uma ruptura objetal drástica, as patologias-limite vão manter-se no registro do arcaico que confunde o Ego, a pulsão e o objeto (Green, 1982) e salvaguardar um elo com o outro graças às organizações perversas. O desenvolvimento de uma relação de domínio, na qual o objeto torna-se tolerável por sua submissão e controle, seja por meio da imposição de sensações ou objetos de substituição, acaba sendo um campo em que os transtornos do comportamento pertencem ao registro aditivo (toxicomania, alcoolismo, transtornos alimentares), havendo o risco de uma ruptura progressiva relacional e de um embotamento sintomático. Atualmente, podemos conceber os estados-limite do adulto como um fracasso nos processos de maturação e subjetivação, próprios da adolescência normal (Cahn, 1998), em particular do "luto" dos objetos primitivos. Essa perspectiva contempla um determinismo precoce exclusivo, apesar das eventualidades da travessia adolescente serem funções de meios psíquicos elaborados previamente.

De uma maneira geral, a evolução desses transtornos depende amplamente da conjuntura e das eventualidades, do quadro familiar mais ou menos suscetível a favorecer ou dificultar esses processos. Daí o interesse pelo conceito "de espaço psíquico ampliado" (Jeammet, 1980) e, no plano terapêutico, de uma abordagem bi ou multifocal (Jeammet, 1992), combinando uma perspectiva psicoterapêutica e uma psiquiátrica e/ou institucional. Finalmente, nesses últimos anos, houve estudos acerca do impacto sobre o trabalho psíquico do adolescente e do jovem adulto em relação às modificações psicossociais contemporâneas menos continentes em relação às pulsões, ao passo que elas aumentam amplamente as expectativas narcisistas e ideais (Jeammet \& Ferro, 2000). 


\section{Síntese atual}

Além da diversidade dos modelos e das concepções teóricas próprias a cada autor, as abordagens características dos estados-limite existentes podem ser ordenadas ao redor de três eixos: problemática dos limites, problemática da perda do objeto e, finalmente, a problemática edipiana e masoquista (Brusset, 1999).

A primeira característica mostra a fragilidade ou, ainda, a fluidez dos limites entre o interior e o exterior do self, uma fragilidade que é fonte de desorganização ou de desmoronamento, que torna necessária a implementação de defesas particulares para possibilitar as trocas entre o interior e o exterior, o sujeito e o objeto. $O$ corolário desse transtorno dos limites diz respeito àquilo que B. Brusset (1999) chama de uma patologia da interioridade e um funcionamento psíquico exteriorizado: o vazio interno, a falta de interioridade e de investimento da atividade psíquica própria explicam a dificuldade em estar só, a dependência do objeto, a busca toxicomaníaca, o desejo de viver a vida que é do outro. Esse déficit no espaço psíquico interno em relação à representação é concebido como o efeito de mecanismos de defesa drásticos, consecutivos à angústia e ao desespero, oriundos das dificuldades de interiorização do objeto: o objeto vem como forma de amenizar os efeitos de sua ausência externa. Ora, esses mecanismos de defesa de ordem primária, com valência destrutiva, nós não retomaremos. Eles agem como estratégias anti-pensamentos (diferentemente do recalque), tendendo a esvaziar o espaço interno para não ter que pensar (e sofrer) de contradições universais, mas inumeráveis, inintegráveis ${ }^{3}$. Essas defesas agem por expulsão na passagem ao ato (atuação), no corpo (somatização) ou ainda no outro (identificação projetiva) e demandam uma repetição. Essa falta de espaço mental desencadeia uma necessidade exacerbada do exterior, de onde surge a dependência ao outro, que é somente uma situação hipotética maior de um super-investimento na realidade externa utilizada para mascarar e remediar o vazio interior.

A problemática e a angústia da perda do objeto é o segundo eixo fundamental de compreensão dos estados-limite (Chabert, 1999a, 1999b). A constante depressiva constitui de fato o núcleo comum dessas organizações, que mostram dificuldades tanto na elaboração da posição depressiva quanto na associação dos afetos e suas representações. Na realidade, é a elaboração da posição depressiva que permite pensar na ausência, assegurando a manutenção da permanência do objeto interno e a integração da ambivalência (movimentos de amor e de ódio) em relação a esse objeto, asseverando, assim, um sentimento de continuidade de existência e um narcisismo positivo. Aqui, pelo fato da força do ódio, a ligação é precária

3 A título de exemplo: para ser você mesmo, primeiramente é preciso aceitar a existência do outro, o mesmo objeto é amado e odiado, quanto mais ele faltar mais ele é odiado e rejeitado e mais ele faz falta etc. 
e aleatória: as possibilidades de continência pulsional são descontínuas e mobilizam as defesas mais primitivas, especialmente a clivagem, que separa partes do objeto.

As organizações e defesas narcísicas podem estar isoladas, mas visam a mesma proteção contra a angústia da perda: proclamação da autossufuciência, idealização e congelamento pulsional. Essas permitem ao sujeito afastar a ameaça da perda que não pode atingi-lo, já que ele é autossuficiente, isolado na carapaça narcisista.

Em contrapartida, nos típicos sujeitos-limite, a hiper-dependência em relação ao objeto exige sua presença constante para amenizar os defeitos de interiorização e lutar contra as pulsões destrutivas (passionais) que formam o inverso. Assim se desenha uma sequência típica:ausência do objeto $=$ perda do objeto $=$ destruição do objeto $=$ culpabilidade $=$ fragmentação = perda de si. A perda do objeto torna-se a perda de si. Mas o ódio (e sua projeção) não tem somente efeitos negativos: além do seu aspecto de liberação do mal interno, assim protegido ele permite uma diferenciação e uma consolidação dos limites frente à ameaça de invasão pelo outro, cuja proximidade pode tornar-se confusa por causa da atração e da dependência a seu respeito. Essa presença é, então, necessária somente por meio de sequências relacionais sado-masoquistas.

Em terceiro lugar, as particularidades da sexualidade edipiana devem ser notadas, pois o Complexo de Édipo não está excluído da compreensão desses casos, mesmo se ele toma aqui um valor mais excitante e passional do que estrutural pelo fato da sexualidade das angústias primitivas, do narcisismo e dos conflitos não libidinosos (Green, 1997). Aqui, a clivagem (bom / ruim), que visa evitar a ambivalência, toca a configuração edipiana, o que repercute sobre as fantasias originais (em particular de cena primitiva e de sedução), que tomam uma coloração sádica, tornando difícil a identificação com as figuras parentais. Os movimentos de ódio, pouco integrados ao amor frente aos pais, acentuam a culpabilidade:"os desejos [mal ou insuficientemente recalcados] são sentidos como forças malignas, impuras e fonte de sofrimento intenso. Manifestam-se principalmente pela amplitude da desqualificação e do menosprezo de si que impõem condutas de sacrifício, visando justamente o corpo e a psique" (Chabert, 1999b, p. 106, a propósito dos transtornos do comportamento alimentar e condutas suicidas compulsivas). A violência destrutiva é massivamente voltada contra si, mas o triunfo ${ }^{4}$ do sacrifício do masoquismo moral traz somente poucos benefícios e necessita, com frequência, de entusiasmo autodestrutivo. Encontramos aqui a marca, em movimentos transferenciais negativos ou na relação terapêutica negativa, que contempla regularmente os tratamentos dos sujeitos-limite: esse último atesta, então, menos da culpabilidade do

4 Triunfo, pois assim a independência é proclamada: Eu quero me fazer mal e me destruir, se assim eu decidir sozinho. 
sujeito que um apego à "doença" pelo fato do medo frente à mudança e à perda $^{5}$ (Chabert, 2003; Chagnon, 2006).

Finalmente, é preciso destacar que, para muitos especialistas, o desaparecimento das neuroses, ligadas à recusa da sexualidade, em proveito das patologias-limite e do mal-estar narcisista que as caracteriza, devem-se às modificações sociais e culturais contemporâneas. Após outros, nós evocamos um novo mal-estar na civilização (Chagnon, 2005): a fragilidade dos quadros familiares, sociais e institucionais, a expectativa dada às tradições, à autoridade, às religiões, às ideologias teriam enfraquecido suas funções protetoras, estimulando e contendo pulsões, ao passo que as exigências de rendimento oriundas da globalização e das mutações tecnológicas, determinando as relações operatórias e sem afetividade, aumentariam as exigências narcisistas, as necessidades de perfeição e o falso ideal. Repercussões clínicas e psicopatológicas ocorrem: recusa da elaboração psíquica dos conflitos, tendência a descarga nos investimentos motores e fálicos, baixa de eficiência da culpabilidade, reduzida tolerância à frustração e à expectativa, busca de estímulos sensoriais imediatamente agradáveis, desinvestimento do pensamento, etc, chegando a uma nova personalidade de base: a personalidade perverso-narcisista e a personalidade depressiva (Lazartigues, 2001).

\section{Conclusão}

Farei a conclusão em três pontos:

Os avanços teórico-clínicos originários do trabalho feito com os estados-limite, que constituiriam um novo paradigma, contribuíram para a renovação da Psicanálise e, ao mesmo tempo, devem-se ao considerável progresso dos psicoterapeutas psicanalistas, sendo impossível citá-los todos aquib.

Mas os mesmos avanços também contribuíram para uma revisão dos critérios diagnósticos, tais como podemos elaborá-los a partir da metodologia projetiva. Permitiram também compreender os limites das organizações neuróticas e psicóticas. Sobre esse aspecto tenho que retomar os trabalhos relativos às técnicas projetivas nos estados-limite e que são bem conhecidas aqui no Brasil: trabalhos de C. Chabert (1998a, 1998b, 2003), F. Brelet (1986), Brelet-Foulard \& Chabert (2003) ou ainda de M. Emmanuelli

5 Uma de nossas pacientes nos disse:"Se eu não sofrer, eu não existo mais".

6 Como o assunto é muito vasto, retomemos três obras recentes: uma sobre a evolução contemporânea da prática analítica em relação com os novos pacientes (Cahn, 2002), a outra sobre o trabalho do psicanalista em psicoterapia (Richard, 2002) e, a última, um panorama quase exaustivo proposto por A.Green. (2006). Enfim, para qualquer questão sobre a abordagem psicanalítica que possa fazer o leitor, indicamos o site Internet da Sociedade Psicanalítica de Paris: www.spp.asso.fr. Aliás, é interessante constatar que os autores que mais escreveram sobre os estados-limite são também aqueles que mais escreveram sobre as psicoterapias psicanalíticas, o que nos mostra indicações de suas escolhas. 
e C. Azoulay (2001), que atualmente estão empenhados em uma pesquisa que visa diferenciar os modos de expressão-limite nos adolescentes e nos adultos (Emmanuelli \& Azoulay, 2008).

Finalmente, a elaboração psíquica sustentada pelos psicanalistas, o que demanda tempo, parece lutar contra o conluio entre as necessidades imediatas e de descargas dos pacientes de stados-limite e as expectativas de uma sociedade tecnocrática, visando, por razões mercantis, uma adaptação frequentemente triste e robótica. Nesse sentido, eles são as garantias de uma abordagem humanista respeitosa da liberdade e da consideração do sujeito.

\title{
Borderline states in french psychoanalytical studies
}

\begin{abstract}
Following a brief introduction to retrace its history along with a terminological clarification, the classical psychopathological tableau of borderline organizations described by Kernberg is summarized in its clinical, structural and genetic dimensions. After the different contemporary psychodynamic schools are mentioned, the major French-language psychoanalytic works concerning both adults (Bergeret, Green) and children and adolescents (Diatkine, Mises, Jeammet) are presented, The theoretical specificity of French psychoanalysis is emphasized in its particular interest which concerns drive as much as object relations, the intrapsychic and the intersubjective realms. A present-day synthesis (Brusset, Chabert) is proposed, which concerns three main problem configurations: borderline pathology and the difficulty of interiority, object-loss anxiety, and the particularities of the oedipal conflict and masochism. The weight of psychosocial and modern cultural modifications upon the changes in psychopathology are mentioned.
\end{abstract}

Keywords: Borderline personality disorder. Object relations. Narcissism. Masochism. Psychoanalytic psychotherapies.

\section{Les états limites dans les travaux psychanalytiques français}

Résumé: Après une brève introduction historique et une clarification terminologique le tableau psychopathologique classique des organisations limites, décrit par Kernberg, est résumé tant dans sa dimension clinique, structurelle que génétique. Les différents courants psychodynamiques contemporains sont rappelés puis les principaux travaux psychanalytiques de langue française sont présentés tant du côté des adultes (Bergeret, Green) que du côté des enfants et des adolescents (Diatkine, Mises, Jeammet). La spécificité théorique de la psychanalyse française attachée tant à la pulsion qu'aux relations d'objet, à l'intrapsychique qu'à l'intersubjectif est soulignée. 
Une synthèse actuelle (Brusset, Chabert) est proposée axée selon trois problématiques principales : la pathologie de l'état-limite, la faute d'intériorisation et la l'angoisse de perte d'objet, les particularités du conflit oedipien et le masochisme. Le poids des modifications psychosociales et culturelles contemporaines sur les changements de la psychopathologie est évoqué.

Mots clés: Trouble de la personnalité limite. Relations d'objet. Narcissisme. Masochisme. Psychothérapies psychanalytiques.

\section{Los estados limitrofes en los trabajos psicoanaliticos franceses}

Resumen: Luego de una breve introducción histórica y una clarificación terminológica, el cuadro psicopatológico clásico de las organizaciones limítrofes, descrito por Kernberg, es resumido tanto en su dimensión clínica como estructural y genética. Las diversas corrientes psicodinámicas contemporaneas son visitadas y los principales trabajos psicoanalíticos en francés son presentados, tanto en adultos (Bergeret, Green) como en niños y adolescentes (Diatkine, Mises, Jeammet). La especificidad teórica del psicoanálisis francés, apegado tanto a la pulsión como a las relaciones de objeto, a lo intra-psíquico como a lo inter-subjetivo, es subrayada. Una síntesis actual (Brusset, Chabert) es propuesta, basada en tres problemáticas principales : la patología de los límites y la falta de interioridad, la angustia de pérdida del objeto, las particularidades del conflicto edipiano y el masoquismo. El peso de las modificaciones psico-sociales y culturales contemporaneas sobre los cambios de la psicopatología es también evocado.

Palabras clave:Transtorno de personalidad limitrofe. Relaciones de objeto.Narcisismo. Masoquismo. Psicoterapia psicoanalitica.

\section{Referências}

Balier, C. (1988). Psychanalyse des comportements violents. Paris: PUF.

Balier, C. (1996). Psychanalyse des comportements sexuels violents. Paris: PUF.

Balier, C. (2005). La violence en abyme. Paris: PUF.

Bergeret, J. (1974). La personnalité normale et pathologique. Paris: Dunod.

Bergeret, J. (1975). La dépression et les états limites. Paris: Payot.

Bergeret, J. (1984). La violence fondamentale. Paris: Dunod. 
Bergeret, J. (1996). La pathologie narcissique. Paris: Dunod.

Bergeret, J., \& Reid, W. (1986). Narcissisme et états limites. Paris: Dunod.

Bourgeois, D. (2004). Comprendre et soigner les états limites. Paris: Dunod.

Braunschweig, D., \& Fain, M. (1971). Eros et Anteros. Paris: Petite Bibliothèque Payot.

Braunschweig, D., \& Fain, M. (1975). La nuit, le jour. Paris: PUF.

Brelet, F. (1986). Le TAT. Fantasme et situation projective. Paris: Dunod.

Brelet-Foulard, F., \& Chabert, C. (2003). Nouveau manuel du TAT : approche psychanalytique. Paris: Dunod.

Brette, F., Emmanuelli, M., \& Pragier, G. (Dir.). (2005). Le traumatisme psychique: Organisation et désorganisation. Paris : PUF. (Monographies de Psychanalyse de la Revue Française de Psychanalyse).

Brusset, B. (1999). Névroses et états limites. In C. Chabert, B. Brusset \& C. BreletFoulard, Névroses et fonctionnements limites (pp. 1-70). Paris: Dunod.

Brusset, B. (2005a). Psychanalyse du lien: les relations d'objet. Paris: PUF.

Brusset, B. (2005b). Métapsychologie du lien et "troisième topique ». Bulletin de la Société Psychanalytique de Paris, pp. 19-88.

Cahn, R. (1998). L'adolescent dans la psychanalyse. L'aventure de la subjectivation. Paris: PUF.

Cahn, R. (2002). La fin du divan. Paris: Odile Jacob.

Casoni, D., \& Brunet, L. (2003). La psychocriminologie. Montréal: Les Presses de I'Université de Montréal.

Chabert, C. (1999a). Les fonctionnements limites: quelles limites? In J. André, Les états limites (pp. 93-122). Paris: PUF.

Chabert, C. (1998a). La psychopathologie à l'épreuve du Rorschach (2ème éd.). Paris: Dunod.

Chabert, C. (1998b). Psychanalyse et méthodes projectives. Dunod: Les Topos.

Chabert, C. (1999b). Problématiques. In C. Chabert, B. Brusset \& C. Brelet-Foulard, Névroses et fonctionnements limites (pp. 71-128). Paris: Dunod.

Chabert, C. (2003). Féminin mélancolique. Paris: PUF.

Chabert, C., Brusset, B., \& Brelet-Foulard, F. (1999). Névroses et fonctionnements limites. Paris: Dunod.

Chagnon, J.-Y. (2005). Hyperactifs ou hypopassifs? Hyperactivité infantile, agressions sexuelles à l'adolescence et nouveau malaise dans la civilisation. La Psychiatrie de I'Enfant, 48(1), 31-88.

Chagnon, J.-Y. (2006). Le masochisme dans les travaux psychanalytiques français: un sujet (dé)battu. Psychologie Clinique et Projective, 12, 57-76.

Chagnon, J.-Y., \& Durand, M. L. (2007). La prépsychose: un concept toujours actuel en psychopathologie de l'enfant? Psychologie Clinique et Projective, 13, 123-171. 
Charrier, P., \& Hirschelmann-Ambrosi, A. (2005). Les états limites. Paris: Armand Colin.

De M'Uzan, M. (1984). Les esclaves de la quantité. In M. De M'Uzan, La bouche de I'inconscient. Essais sur l'interprétation (pp. 155-168). Paris: Gallimard.

De M'Uzan, M. (1997). Genèse du symptôme somatique. Trois hypothèses théoriques et suivi d'une cure in cliniques psychosomatiques. In Monographies de la Revue Française de Psychanalyse (pp. 29-45). Paris: PUF.

Doucet, P, \& Reid, W. (1996). La psychothérapie psychanalytique. Une diversité de champs cliniques. Montréal: Gaëtan Morin.

Emmanuelli, M., \& Azoulay, C. (2001). Les épreuves projectives à l'adolescence, approche psychanalytique. Paris: Dunod.

Emmanuelli, M., \& Azoulay, C. (2008). Spécificité des troubles limites à l'adolescence: contribution des épreuves projectives au diagnostic. Communication au XIXième Congrès de I'ISR, Louvain.

Fain, M. (1971). Prélude à la vie fantasmatique. Revue Française de Psychanalyse, (2-3), 291-364.

Freud, S. (1978). Pulsions et destin des pulsions. In S. Freud, Métapsychologie (pp. 1144). Paris: Gallimard. (Trabalho original publicado em 1915)

Freud, S. (1985). L'analyse sans fin et l'analyse avec fin. In S. Freud, Résultats, idées, problèmes II (pp. 269-281). Paris: PUF. (Trabalho original publicado em 1937)

Green, A. (1974). L'analyste, la symbolisation et l'absence dans le cadre analytique. In A. Green, La folie privée. Psychanalyse des cas-limites (pp. 63-102). Paris: Gallimard.

Green, A. (1976). Le concept de limite. In A. Green, La folie privée. Psychanalyse des caslimites (pp. 103-140) Paris: Gallimard.

Green, A. (1980). Passions et destins des passions. Sur les rapports entre folie et psychose. In A. Green, La folie privée. Psychanalyse des cas-limites (pp. 141-193). Paris: Gallimard.

Green, A. (1982). Après coup, I'archaïque. In A. Green, La folie privée. Psychanalyse des cas-limites (pp. 282-253). Paris: Gallimard.

Green, A. (1983). Narcissisme de vie narcissisme de mort. Paris: Les Editions de Minuit.

Green, A (1987). La capacité de rêverie et le mythe étiologique. In A. Green, La folie privée. Psychanalyse des cas-limites (pp. 347-368), Paris: Gallimard.

Green, A. (1990). La folie privée. Psychanalyse des cas-limites. Paris: Gallimard.

Green, A. (1993). L'analité primaire. In A. Green A. La pensée clinique (pp. 111-147). Paris: Odile Jacob.

Green, A. (1997). Les chaînes d'Eros. Actualité du sexuel. Paris: Odile Jacob.

Green, A. (1999a). Genèse et situation des états limites. In J. André J., Les états limites (pp. 23-67). Paris: PUF.

Green, A. (1999b). Sur la discrimination et l'indiscrimination affect-représentation. In A. Green, La pensée clinique (pp. 189-257). Paris: Odile Jacob. 
Green, A. (2002a). La pensée clinique. Paris: Odile Jacob.

Green, A. (2002b). Idées directrices pour une psychanalyse contemporaine. Paris: PUF.

Green, A. (Dir.). (2006). Les voies nouvelles de la thérapeutique psychanalytique. Le dedans et le dehors. Paris: PUF.

Green, A., \& Donnet J.-L. (1973). L'enfant de ça. Paris: Editions de Minuit.

Guilé, J.-M. (2004a). Etats limites et troubles de la personnalité: théorie, clinique, recherches (1). Perspectives Psy, 43(4), 259-295.

Guilé, J.-M. (2004b). Etats limites et troubles de la personnalité: théorie, clinique, recherches (2). Perspectives Psy, 43(5), 343-381.

Jeammet, P. (1980). Réalité externe et réalité interne. Importance et spécificité de leur articulation à l'adolescence. Revue Française de Psychanalyse, (3-4), 481-521.

Jeammet, P. (1992). La thérapie bifocale. Adolescence (Psychothérapies 2), 10(2).

Jeammet, P. (1994). Adolescence et processus de changement. In D. Wildocher, Traité de psychopathologie (Chap. 23, pp. 637-726). Paris: PUF.

Jeammet, P., \& Corcos, M. (2005). Evolution des problématiques à l'adolescence L'émergence de la dépendance et ses aménagements (2ème éd.). RueilMalmaison: Doin.

Jeammet, P., \& Ferro, M. (2000). Que transmettre à nos enfants? Paris: Editions du Seuil.

Kernberg, O. (1975). Les troubles limites de la personnalité. Paris: Privat, 1979.

Kernberg, O. (1984). Les troubles graves de la personnalité: stratégies psychothérapiques. Paris: PUF.

Kreisler, L. (1976). La psychosomatique de l'enfant. Paris: PUF.

Kreisler, L., Fain, M., \& Soulé, M. (1974). L'enfant et son corps. Paris: PUF.

Ladame, F. (1987). Les tentatives de suicide chez les adolescents (2ème éd.). Paris: Masson.

Ladame, F. (1998). Etat limite et adolescence. La psychiatrie de l'enfant, 41(2), 545-562.

Lazartigues, A. (2001). La famille contemporaine « fait »-elle de nouveaux enfants? Neuropsychiatrie de l'Enfance et de l'Adolescence, 49(4), 264-276.

Lussier, A. (1975). Essai sur l'idéal du moi. Thèse de doctorat, Département de Psychologie, Université de Montréal.

Lussier, A. (2006). La gloire et la faute. Essai psychanalytique sur le conflit qui oppose narcissisme et culpabilité. Québec: Presses de I'Université du Québec.

Marty, F., \& Chagnon, J.-Y. (2006). Identité et identification à l'adolescence. Encyclopédie Médico Chirugicale (Psychiatrie/pédopsychiatrie), 37-213-A-30.

Marty, P., De M'Uzan, M., \& Christian, D. (1963). L'investigation psychosomatique. Paris: PUF.

Marty, P. (1990). La psychosomatique de l'adulte. Paris: PUF. 
Mc Dougall, J. (1978). Plaidoyer pour une certaine anormalité. Paris: Gallimard.

Mc Dougall, J. (1982). Théâtres du Je. Paris: Gallimard.

Mc Dougall, J. (1989). Théâtres du corps. Paris: Gallimard.

Mc Dougall, J. (1996). Eros aux mille et un visages. Paris: Gallimard.

Palacio-Espasa, F., \& Dufour, R. (1995). Diagnostic structurel chez l'enfant. Paris: Masson.

Quinodoz, J.-M. (1991). La solitude apprivoisée. Paris: PUF.

Richard, F. (2002). Le travail du psychanalyste en psychothérapie. Paris: Dunod.

Roussillon, R. (1991). Paradoxes et situations limites de la psychanalyse. Paris: PUF.

Roussillon, R. (1999). Agonie, clivage et symbolisation. Paris: PUF.

Smadja, C. (2001). La vie opératoire. Etudes psychanalytiques. Paris: PUF.

Szwec, G. (1998). Les galériens volontaires. Paris: PUF.

Widlocher, D. (1984). Le psychanalyste devant les problèmes de classification. Confrontations Psychiatriques, (24), 141-157.

Jean Yves Chagnon, Psicólogo clínico, Psicanalista, Mestre de Conferências HDR, Laboratório de Psicologia Clinica e de Psicopatologia,Instituto dePsicologia,Universidade Paris-5, Descartes, Paris, França. Endereço eletrônico: jean-yves.chagnon@univ-paris5.fr

Recebido em: 5/12/2008

Aceito em: 30/03/2009 